\title{
A PERSPECTIVA DO ALUNO NA PESQUISA ACADÊMICA: INICIAÇÃO CIENTÍFICA EM EAD
}

\author{
LONDRINA/PR MAIO/2018
}

\author{
Fábio Luiz da Silva - Unopar - fls.londrina@yahoo.com.br \\ Julho Zamariam - Unopar - julho.zamariam@unopar.br \\ Fabiane Tais Muzardo - Unopar - fabiane2@unopar.br \\ Fabiane Luzia Menezes Santos - Unopar - fabiane.menezes@unopar.br
}

Tipo: Relato de Experiência Inovadora (EI)
Categoria: Métodos e Tecnologias
Setor Educacional: EDUCAÇÃO SUPERIOR

RESUMO

A Iniciação Científica é uma importante contribuição das universidades para o desenvolvimento da pesquisa e da ciência. No entanto, ela está concentrada nas universidades públicas. Nas instituições privadas, é raro encontrarmos iniciativas nesse sentido. Nos cursos na modalidade de Ensino a Distância (Ead), tal prática envolve uma série de desafios. Assim, esse artigo tem por objetivo apresentar a perspectiva do aluno da modalidade Ead em relação à sua participação em projeto de pesquisa. Trata-se de uma pesquisa realizada com graduandos de licenciatura de três cursos. Nesse texto, apresentamos e comentamos a resposta desses alunos a um questionário atitudinal que pretendeu verificar a perspectiva dos discentes participantes. Podemos afirmar, a partir disso, que a experiência foi de grande valia para os alunos e que serão necessários ajustes para futuras atividades semelhantes.

Palavras-chave: Ensino, Iniciação Científica, Ensino a Distância. 


\section{Introdução}

No Brasil, existem diversos programas de Iniciação Científica (IC). Esses programas são destinados a alunos de graduação - em alguns casos também a alunos de Ensino Médio -, que têm a oportunidade de participar de projetos de pesquisa sob orientação de um professor. Essa atividade proporciona aos alunos conhecimento sobre técnicas e métodos de pesquisa, o que, além de desenvolver o pensamento científico, estimula a produção de novos conhecimentos. O surgimento de uma política de IC nas universidades brasileiras ocorreu no início da década de 1950, quando foi criado o Conselho Nacional de Desenvolvimento Científico e Tecnológico (CNPq). A partir dessa época, bolsas de estudo passaram a ser ofertadas aos alunos de graduação que participassem de projetos de pesquisa em suas universidades (MASSI; QUEIROZ, 2010). Atualmente, além do CNPq, existem instituições regionais de fomento à pesquisa que possuem programas de IC.

No entanto, a maior parte das bolsas de IC estão nas universidades públicas, sustentadas pelo governo. Salvo algumas exceções - como as universidades católicas inexiste no Brasil uma tradição de pesquisa científica nas universidades privadas, que se dedicam quase exclusivamente ao ensino (MASSI; QUEIROZ, 2010). Há, portanto, grande quantidade de alunos do Ensino Superior que não tem acesso a programas de IC. Essa situação é mais grave no caso das instituições que oferecem educação a distância (e-Learning). Com milhares de alunos em cada curso, espalhados pelo extenso território brasileiro, essas universidades enfrentam um desafio ainda maior para a oferta desse tipo de atividade àqueles que nelas estudam.

A Unopar é uma universidade privada localizada na cidade de Londrina, norte do estado do Paraná. Além de cursos presenciais, essa instituição oferta diversos cursos de graduação na modalidade de Educação a Distância (Ead). Em 2016, professores dessa universidade começaram a desenvolver um projeto que permitiu aos alunos participar de pesquisas científicas, na qualidade de aprendizes, mesmo que morassem distantes da sede da universidade. Surgiu, então, o Projeto de Iniciação Científica em Educação a Distância (PIC-Ead), idealizado por uma docente da mesma instituição. Nesse mesmo ano, houve a implementação das primeiras experiências, que serviram para o aperfeiçoamento da proposta inicial.

O projeto a que se refere esse texto faz parte das iniciativas que surgiram após aquela experiência inicial e nosso objetivo, nesse artigo, é apresentar a perspectiva do aluno da modalidade Ead em relação à sua participação em projeto de pesquisa. 


\section{Referencial teórico e procedimentos}

No início de 2017, a Unopar solicitou aos professores interessados que apresentassem projetos de pesquisa que possibilitassem a participação de alunos da modalidade a distância (e-Learning) em atividades de Iniciação Científica. Em razão disso, apresentamos à instituição o seguinte projeto "Gestão da Sala de Aula em escolas da Educação Básica: identificando o uso de estratégias eficientes". Foram convidados a participar do projeto alunos das licenciaturas em História, Artes Visuais e Pedagogia que estivessem entre o $4^{\circ}$ e $07^{\circ}$ semestres, pelo fato de, nesses semestres, eles realizarem os estágios obrigatórios, que incluem desde observação em sala de aula até a regência propriamente dita, ou seja, esses alunos já estão inseridos no ambiente escolar. Inicialmente, nosso objetivo foi o de aproximar esse aluno da pesquisa cientifica, por meio de leituras de textos e participação em fóruns e chats de discussão online.

Em seguida, esses alunos foram convidados a aplicar dois instrumentos de pesquisa nas escolas em que já realizavam o estágio obrigatório. O primeiro instrumento, construído a partir de pesquisas internacionais sobre eficácia escolar (REYNOLDS et al, 2002), questiona sobre quais práticas de gestão os professores do ensino básico costumam realizar em sala de aula para melhorar a qualidade do ensino oferecido. $O$ segundo, por sua vez, visava identificar as práticas realizadas pelo professor diante da indisciplina em sala de aula e sua reincidência (NASEY, 2012).

Para desenvolver as atividades previstas, foi criado um Ambiente Virtual de Aprendizagem utilizando o Moodle (Modular Object Oriented Distance Learning), que é um software livre para criação de cursos à distância. Na primeira chamada para o projeto, vinte e dois alunos inscreveram-se, mas apenas dois enviaram a documentação necessária. Em virtude da baixa procura pelo projeto, elaborou-se uma segunda chamada. Decidiu-se investir na divulgação durante as teleaulas. Utilizamos alguns minutos das aulas para falar a respeito do projeto. Essa estratégia parece ter funcionado, pois 99 alunos inscreveram-se. Dessa vez, mantivemos contato semanal com os alunos inscritos para que eles nos enviassem a documentação necessária para a efetivação da matrícula no projeto de pesquisa. Dos 99 inscritos, 31 concluíram a matrícula e iniciaram as atividades, ou seja, mais de $30 \%$.

As atividades do projeto dividiram-se em três fases. Na primeira, os alunos tiveram contato com os principais conceitos necessários a uma pesquisa científica, inclusive sobre ética, por meio de web-aulas que intercalavam vídeos e textos. Após os alunos acessarem todas as web-aulas, eles realizaram uma avaliação cuja aprovação dava acesso às atividades do nível 2. Enquanto o nível 1 tratava da pesquisa de forma 
genérica, o nível 2 apresentava textos sobre a temática desse projeto. Os alunos deveriam realizar resumos desses textos e enviar por e-mail para os professores orientadores. Nesse nível, foi apresentado aos alunos um vídeo produzido pelos professores que orientava sobre como proceder na coleta de dados. Os alunos foram, então, orientados a realizar as atividades do nível 3, que consistiam em entrar em contato com a escola, solicitar as autorizações necessárias, conseguir a concordância dos participantes, aplicar os instrumentos de pesquisa e analisar os dados obtidos. Em todos os níveis a comunicação entre professores e alunos ocorreu por meio de e-mail e de chats semanais.

O projeto encontra-se na fase final, de entrega dos relatórios produzidos pelos alunos. Além disso, eles responderam uma pesquisa atitudinal, que servirá para que nós possamos avaliar a validade da metodologia elaborada, desde o acesso a plataforma e aos materiais, até a autoavaliação com relação as suas participações no projeto.

\section{Apresentação e discussão dos resultados}

A pesquisa atitudinal contou com 5 questões abertas que tentaram mapear as possíveis dificuldades que os alunos poderiam ter no desenvolvimento do projeto. Na primeira questão ("Você teve facilidade em acessar os materiais disponibilizados na plataforma? Em caso negativo, explique brevemente qual foi a dificuldade") todos os participantes responderam positivamente, demonstrando que, como estão acostumados com o ensino à distância, uma vez que estão no mínimo no $4^{\circ}$ semestre dos seus cursos, tiveram facilidades com a plataforma, mesmo que ela seja diferente da que utilizam normalmente na instituição, que possui sistema próprio de acesso dos alunos aos seus materiais, o AVA (Ambiente Virtual de Aprendizagem).

$\mathrm{Na}$ segunda questão ("Qual a sua opinião sobre os materiais disponibilizados no 'Treinamento Nível 1' (webaulas 1 a 8 sobre pesquisa científica, Currículo Lattes, Banco de Dados, Ética na Pesquisa e Projeto de Pesquisa)?") três alunos afirmaram que gostaram dos materiais, achando-os esclarecedores. Um aluno, citado aqui como Aluno 3, elogiou os materiais escritos, mas nos chamou a atenção a afirmação de que não gostou dos vídeos disponibilizados, afirmando que "poderiam ter sido bem mais detalhados". Diante disso, novos vídeos instrucionais foram produzidos e estarão disponíveis para a próxima turma.

A terceira questão foi subdivida em três partes: "Dos artigos disponibilizados no "Nível 2 - Leitura de Textos": a) Conseguiu acessá-los com facilidade?" somente o Aluno 1 afirmou ter dificuldades. Como todos os outros acessaram os textos com facilidade, 
pressupomos que esse problema isolado deva ter ocorrido por conta de uma dificuldade particular desse aluno e não por uma falha da plataforma. Reforça esse pensamento 0 fato de que o aluno não nos procurou nem por e-mail nem por chat para relatar a dificuldade, o que pressupõe que ele conseguiu resolver esse problema sozinho e sem grandes demandas. Já na segunda parte da questão "b) teve dificuldade com a leitura?", novamente o Aluno 1 disse ter tido dificuldade, sem expressar, contudo, qual foi. Como ele também teve dificuldade no acesso ao texto, acreditamos que ele apenas reforçou essa dificuldade na parte "b" da questão 3. Todos os outros alunos afirmaram que não tiveram dificuldades na leitura dos textos, o que nos aponta um aspecto positivo do material disponibilizado. Na terceira parte da questão 3 "teve suas dúvidas sanadas (por e-mail e/ou chat)?" todos os alunos responderam positivamente. O Aluno 2 afirmou que "Sim, sempre que tive dúvidas elas foram sanadas, utilizei com maior frequência o email que foi respondido sempre em tempo hábil. O fórum utilizei muito pouco, mas quando utilizei também foi respondido com rapidez e sanou minhas dúvidas." Ficamos bastante satisfeitos com essa devolutiva, uma vez que era uma das nossas principais preocupações o atendimento adequado aos alunos, reforçando o nosso pressuposto de que o desenvolvimento de projetos de pesquisa à distância é possível e necessário.

A quarta questão também ficou dividida em três partes: "Quanto às orientações para a aplicação dos questionários: a) as orientações foram suficientes? b) conseguiu imprimir todos os documentos necessários com facilidade? c) os vídeos disponibilizados foram de fácil acesso e úteis?", o Aluno 1 disse que deveriam ter mais vídeos, para facilitar mais o entendimento. Todos os demais alunos responderam as questões positivamente, reforçando a contribuição dos vídeos no entendimento das tarefas a serem realizadas. Com base nas respostas obtidas nessa questão, e refletindo sobre a questão 2 , na qual também surgiu uma sugestão pedindo para que os vídeos fossem mais detalhados, estamos repensando o formato e quantidade de vídeos de orientação à serem disponibilizados no próximo edital, com o intuito de incentivar e facilitar ainda mais a participação dos alunos, sem, contudo, sobrecarregá-los com muitas informações, desmotivando o processo das leituras e da construção da experiência na IC.

Na quinta questão respondida, "Quanto à análise dos questionários: a) as orientações foram suficientes? b) conseguiu relacionar as leituras realizadas com os questionários que aplicou?" nos chamou a atenção duas respostas que fugiram da simplicidade afirmativa. O Aluno 2 afirmou que "foi possível relacionar as leituras com a pesquisa realizada, ampliando meus conhecimentos sobre a GSA (Gestão de Sala de Aula)". Essa resposta nos deixou bastante satisfeitos, porque percebemos que o aluno conseguiu alcançar autonomia na interpretação do objetivo do projeto, fazendo a relação entre a teoria apresentada e a prática. Outra resposta, no entanto, gerou outro 
sentimento. O Aluno 3 disse que "Eu senti necessidade de mais discussão, mas não somente dos professores, mas principalmente dos colegas, acredito que a troca de ideias proporciona um maior entendimento. Confesso que fiquei um pouco perdida. No primeiro que participei, houve uma maior interação por parte dos alunos, e a contribuição dos demais, junto ao dos professores orientadores ajudava bastante a construir as categorias de análise, a relacionar os textos com o questionário.". Nesse relato, percebemos uma dificuldade inerente a IC na EaD: a troca de experiência entre os participantes do projeto. As discussões que sempre surgem em qualquer projeto de pesquisa são fundamentais e enriquecem a produção do conhecimento realizada em qualquer experiência de IC, o que, segundo esse aluno, deixou a desejar nesse projeto. Contudo, o próprio aluno afirma que em outro projeto que participou a interação foi diferente, o que nos faz entender que essa dificuldade não deva ser tão inerente assim aos projetos de IC na educação à distância, mas uma dificuldade momentânea do nosso projeto. Todavia, temos que salientar também que essa foi a fala de um aluno, o que não pode ser levado como verdade única de todos os participantes do projeto.

Após as cinco questões, fizemos uma última pergunta de cunho mais pessoal a todos os discentes: "Para finalizar, qual sua opinião sobre o projeto? Você considera que a participação nesse projeto colaborou para sua formação?". Essa questão despretensiosa veio a ser a mais interessante de todas a pesquisa atitudinal. Com uma pergunta mais abrangente, percebemos que os alunos se sentiram mais à vontade para expressar suas opiniões. O Aluno 1 disse que: "O projeto é muito interessante para nossa formação como professor, através das perguntas respondidas pelos professores podemos ter alguma noção do que vamos utilizar dentro de sala de aula, olhar qual estratégia pode ser melhor para ser usada dentro dado contexto, apesar que cada professor possui uma estratégia diferente." O Aluno 2 afirmou que "A participação no projeto tem contribuído de maneira muito significativa na minha formação geral pedagógica, apliquei diversos conceitos assimilados através do projeto nos meus estágios de Séries Iniciais do Ensino Fundamental e Gestão Escolar, pois em ambos desenvolvi projetos referentes à indisciplina escolar." O Aluno 3 apontou que: "Todo conhecimento científico adquirido contribui para a formação acadêmica, nos dá um novo olhar sobre questões que são pertinentes à prática educativa. Não é uma receita pronta de como podemos ser eficientes a sala de aula, mas nos direciona qual caminho seguir ou não nesse sentido." E o Aluno 4 explicou que "O projeto ajudou no contato com a profissão e com a Academia. Desenvolveu o conhecimento, coletar e analisar dados, e tirar conclusões. Participação do projeto colaborou na minha formação com mais experiência dentro de minha área."

\section{Considerações finais}


Todas essas respostas nos deixaram extremamente satisfeitos com o projeto, porque percebemos que nossos alunos tiveram um bom contato com a iniciação científica e que gostaram da experiência. Além disso, todos conseguiram relacionar o projeto e sua base ideológica a prática pedagógica e a gestão da sala de aula, compreendendo a importância do tema e da valorização das experiências de outros professores em sala de aula, que conseguem, apesar das diversas dificuldades que a docência apresenta no nosso país atualmente, desenvolver estratégias positivas no cotidiano escolar. Esperamos o mais breve possível catalogar e apresentar os resultados dos instrumentos que os alunos do projeto aplicaram com os professores, apresentando as estratégias por eles desenvolvidas na gestão eficiente da sala de aula.

Dos trinta e um alunos que se inscreveram, onze concluíram o projeto. Considerando a quantidade de alunos matriculados nos três cursos envolvidos, o número que se matriculou e finalizou o projeto é pequeno. Porém, trata-se de uma experiência pioneira, levando em conta a modalidade de ensino e o fato de ser uma instituição privada, onde a cultura de pesquisa encontra-se em estágio inicial.

\section{Referências}

MASSI, L.; QUEIROZ, S. L. Estudos sobre a iniciação científica no Brasil: uma revisão. Cadernos de Pesquisa, v.40, n.139, jan./abr., 2010, p.173-197. Disponível em: . Acesso 15 fev. 2018.

NASEY, C. (2012). Teachers' use of classroom-based management strategies: a survey of New Zealand teachers. Dissertação (Mestrado em Psicologia Educacional). 107f. Massey University, Albany, New Zeeland, 2012. Disponível em: .

REYNOLDS at al. World class schools: internacional perspectives on school effectiveness. London/New York: Routledge, 2002. 